\title{
Regulation of Phosphofructokinase from Aspergillus niger: Effect of Fructose 2,6-Bisphosphate on the Action of Citrate, Ammonium Ions and AMP
}

\author{
By EUGEN ARTS, † CHRISTIAN P. KUBICEK* AND MAX RÖHR \\ Institut für Biochemische Technologie und Mikrobiologie, TU Wien, Getreidemarkt 9 , \\ A-1060 Wien, Austria
}

(Received 2 September 1986; revised 28 November 1986)

\begin{abstract}
The role of fructose 2,6-bisphosphate in the regulation of glycolysis in the citric acid accumulating fungus Aspergillus niger was investigated. Fructose 2,6-bisphosphate stimulated the activity of partially purified phosphofructokinase by increasing the affinity of the enzyme for fructose 6-phosphate and relieving inhibition by ATP. Fructose 2,6-bisphosphate acted synergistically with AMP, but not with $\mathrm{NH}_{4}^{+}$ions, which otherwise also activate phosphof ructokinase. Fructose 2,6-bisphosphate also partially antagonized citrate inhibition of phosphofructokinase; complete deinhibition against high $(5 \mathrm{mM})$ concentrations of citrate (as occur during citric acid accumulation), however, required the simultaneous presence of fructose 2,6bisphosphate $(0 \cdot 1 \mu \mathrm{M})$, AMP $(0 \cdot 1 \mathrm{mM})$ and $\mathrm{NH}_{4}^{+}$ions $(20 \mathrm{mM})$.
\end{abstract}

\section{INTRODUCTION}

The discovery that Fru 2,6- $\mathrm{P}_{2}$ (fructose 2,6-bisphosphate) is an activator of PFK in liver cells opened new insights into the mechanism of glycolytic regulation (Van Schaftingen et al., 1980a, b). The formation of Fru 2,6- $\mathrm{P}_{2}$ is triggered in response to glucose supply; it is active at nanomolar concentrations and it stimulates PFK [ATP:D-fructose-6-phosphate 1-phosphotransferase ('phosphofructokinase'); EC 2.7.1.11] by shifting its $[S]_{0.5}$ value for Fru 6-P (fructose 6-phosphate) to lower, physiological concentrations and abolishing inhibition by ATP (Van Schaftingen et al., 1981). Since most other modifiers of PFK (citrate, AMP) act by affecting ATP binding (Ogawa \& Atkinson, 1985), Fru 2,6- $\mathrm{P}_{2}$ occupies a key position in the regulation of this enzyme.

We are investigating the regulation of glycolysis in the fungus Aspergillus niger in relation to its ability to accumulate high concentrations of citric acid, and have shown that PFK is a major control point (Habison et al., 1979; 1983; Meixner-Monori et al., 1984; Schreferl et al., 1986). Several lines of evidence have led to the assumption that citrate accumulates in this fungus because the feedback control of PFK by citrate is relieved by high intracellular concentrations of $\mathrm{NH}_{4}^{+}$ions (Röhr \& Kubicek, 1981; Kubicek \& Röhr, 1986). The influence of Fru 2,6-P however, has so far not been investigated.

Effects of Fru 2,6- $\mathrm{P}_{2}$ that are similar, but not identical, to those that occur in higher eukaryotic systems have been demonstrated with purified PFK from Saccharomyces cerevisiae (Bartrons et al., 1982) and with crude extracts from Phycomyces blakesleeanus (Van Laere, 1983). In the present paper we report studies on the effect of Fru 2,6- $\mathrm{P}_{2}$ on partially purified PFK from A. niger.

† Present address: Department of Genetics, Agricultural University, 53 Generaal Foulkesweg, 6703 BM Wageningen, The Netherlands.

Abbreviations: Fru 6-P, fructose 6-phosphate; Fru 2,6-P , fructose 2,6-bisphosphate; PFK, ATP :D-fructose-6phosphate 1-phosphotransferase (EC 2.7.1.11). 


\section{METHODS}

Organism and conditions for growth. Aspergillus niger B60, a citric acid producing strain, was used throughout these studies. Its maintenance, as well as conditions for growth under citric acid producing and non-producing conditions, were described by Kubicek \& Röhr (1978) and Habison et al. (1983).

Preparation of cell-free extracts and partial purification of PFK. This was done by following exactly procedures described by Habison $e t$ al. (1983). The final preparation had a specific activity of $6( \pm 0.5) \mathrm{U}$ (mg protein) ${ }^{-1}$ and was essentially free of several enzymes capable of reacting with the substrates or potential effectors of PFK. The preparation was used for kinetic studies within $72 \mathrm{~h}$, during which time it did not lose more than $25( \pm 7) \%$ of its activity $\left(4^{\circ} \mathrm{C}\right)$. It was shown in separate experiments that the partial loss in activity did not lead to a change in the regulatory properties.

Assay of PFK activity and kinetic investigations. PFK activity was measured spectrophotometrically by coupling with aldolase, triose phosphate isomerase and glycerol-3-phosphate dehydrogenase, and measuring the decrease in $\mathrm{NADH}$ at $340 \mathrm{~nm}$. [One unit $(\mathrm{U})$ is defined as the decrease of $2 \mu \mathrm{mol}$ NADH per min under the conditions of the assay.] Unless stated otherwise, the conditions reported by Habison et al. (1983) were used. $\mathbf{M g}^{2+}$ ions were always maintained at twice the ATP concentration. Kinetic constants were determined as reported by Habison $e t$ al. (1983).

Chemicals. Fru 2,6-P was obtained from Calbiochem; Dextran-Blue Sepharose 4B was from Pharmacia. Enzymes and substrates were from Boehringer. All other reagents were of analytical grade.

\section{RESULTS}

The effect of Fru 2,6-P on the saturation curve of $A$. niger PFK for its two substrates, Fru 6-P and ATP, is shown in Fig. $1(a, b)$. It appears that Fru 2,6-P 2 at less than $1.0 \mu \mathrm{M}$ increased the affinity of PFK for Fru 6-P and decreased inhibition by ATP. In contrast to reports on $S$. cerevisiae and P. blakesleeanus PFK, but in agreement with reports on the enzyme from several mammalian tissues (Bartrons et al., 1982; Van Laere, 1983; Van Schaftingen et al., 1981; Heylen et al., 1982), the presence of Fru 2,6- $\mathrm{P}_{2}$ did not increase $V_{\max }$. With Fru 6-P concentrations between 0.47 and $1 \mathrm{mM}$ half maximum stimulation was obtained at $0 \cdot 1-0 \cdot 2 \mu \mathrm{M}-\mathrm{Fru} 2,6-\mathrm{P}_{2}$ (Fig. $1 c$ ). This value is similar to that reported for the enzyme from most other sources, but significantly lower than that for $S$. cerevisiae PFK.

We reported recently that the affinity of $A$. niger PFK for its substrate Fru 6-P can be modulated by AMP, $\mathrm{NH}_{4}^{+}$ions and citrate (Habison et al., 1983), as is the case for PFK from several other eukaryotic tissues and cells (Uyeda, 1979). We have now investigated the effect of Fru 2,6- $\mathrm{P}_{2}$ on the action of these effectors of $A$. niger PFK (Figs 2 and 3). Again, in contrast to the reports on $S$. cerevisiae and $P$. blakesleeanus PFK but in agreement with reports on the mammalian enzyme (Bartrons et al., 1982; Van Laere, 1983; Heylen et al., 1982; Hers \& Van

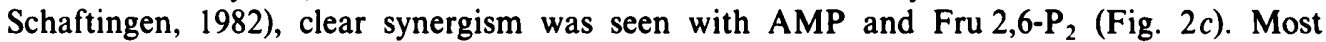
importantly, this synergism was seen at AMP concentrations of about $0.1 \mathrm{mM}$, which actually occur in vivo in $A$. niger (Habison et al., 1983). Synergistic modulation of PFK affinity for Fru 6-P by AMP and Fru 2,6-P $\mathrm{P}_{2}$ is thus probably of physiological importance. In contrast $\mathrm{NH}_{4}^{+}$ions, which also increase PFK affinity toward Fru 6-P, exhibited no synergism with Fru 2,6- $\mathrm{P}_{2}$ (Fig. 2c).

Citrate is a strong inhibitor of $A$. niger PFK, even at concentrations as low as $0.1 \mathrm{mM}$ (Habison et al., 1983); it acts by decreasing the affinity of PFK for Fru 6-P. At 5 mM-citrate, $[S]_{0.5}$ for Fru 6-P was $12 \mathrm{mM}$, indicating complete inhibition at physiological Fru 6-P concentrations $(0 \cdot 1-$ $0.2 \mathrm{mM}$; Habison et al., 1983). Fru 2,6- $\mathrm{P}_{2}$ and AMP were both able to considerably relieve PFK from this inhibition (Fig. 3a); however, even when AMP and Fru 2,6-P $\mathrm{P}_{2}$ were present simultaneously, $[S]_{0.5}$ for Fru 6-P was $0.5 \mathrm{~mm}$, indicating considerable inhibition under physiological conditions.

Citrate inhibition of $A$. niger PFK is counteracted by high concentrations of $\mathrm{NH}_{4}^{+}$ions (Habison et al., 1983); such concentrations are found in mycelia of $A$. niger under conditions of citric acid fermentation (cf. Röhr \& Kubicek, 1981). We have now shown that the simultaneous presence of high concentrations of $\mathrm{NH}_{4}^{+}$ions, Fru 2,6-P $\mathrm{P}_{2}$ and AMP completely abolishes the effect of citrate (Fig. $3 b$ ) when compared to the control in the absence of citrate (cf. Fig. $2 b$ ). Under these conditions, the $[S]_{0.5}$ value for Fru 6-P was $0.1 \mathrm{mM}$, which closely resembles the Fru 6-P concentration in $A$. niger mycelia in vivo (Habison et al., 1983). 

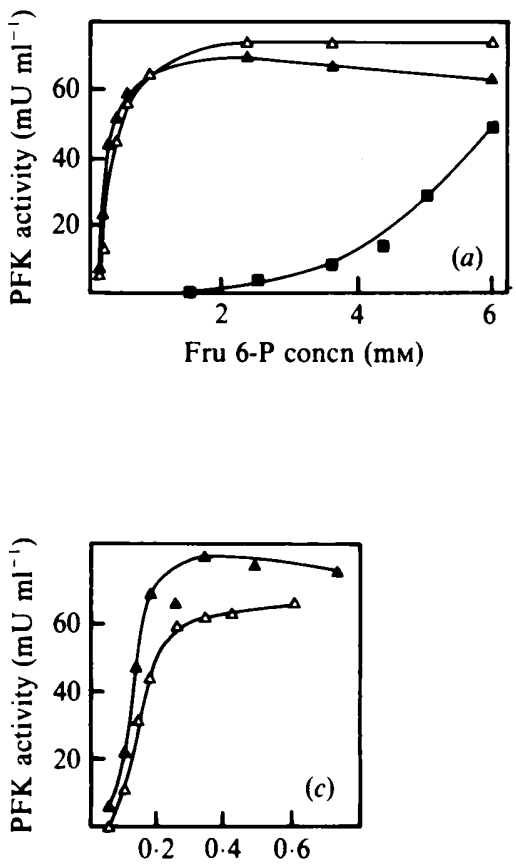

Fru 2,6-P concn $(\mu \mathrm{M})$

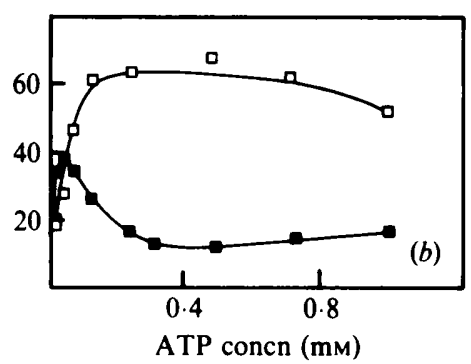

Fig. 1. (a) Effect of Fru 6-P concentration on PFK activity in the absence ( $\square$ ) or presence of $0.2 \mu \mathrm{M}(\omega)$ or $0.4 \mu \mathrm{M}(\triangle)$ Fru $2,6-\mathrm{P}_{2} ;(b)$ effect of ATP concentration on PFK activity in the absence ( $\square$ ) or presence $(\square)$ of $0.2 \mu \mathrm{M}$ Fru 2,6- $\mathrm{P}_{2} ;(c)$ effect of Fru 2,6- $\mathrm{P}_{2}$ concentration on PFK activity in the presence of $0.47 \mathrm{~mm}(\triangle)$ or $1 \mathrm{~mm}(\triangle)$ Fru 6-P. All results shown were obtained from a single experiment but repetition yielded consistent results. The concentrations of ATP and Fru 6-P were $0.1 \mathrm{mM}$ and $5 \mathrm{mM}$, respectively, unless otherwise indicated.

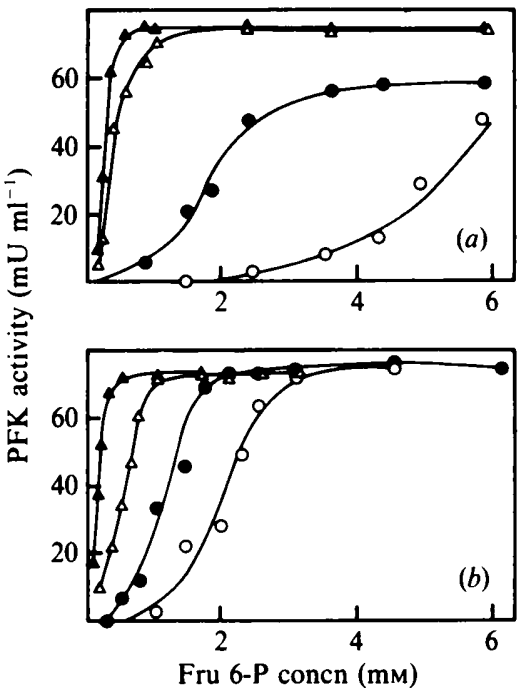

Fig. 2

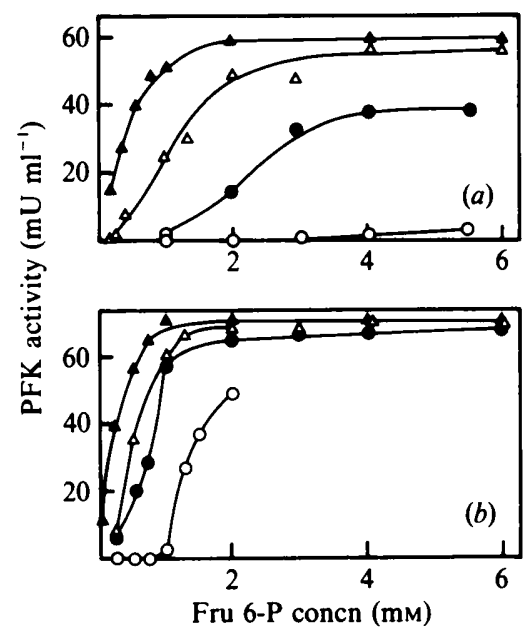

Fig. 3

Fig. 2. Effect of Fru 6-P concentration on PFK activity as influenced by various effectors in the absence $(a)$ or presence $(b)$ of $20 \mathrm{mM}-\mathrm{NH}_{4}^{+}: O$, control; $O$, control plus $0.1 \mathrm{mM}-\mathrm{AMP} ; \triangle$, control plus $0.2 \mu \mathrm{M}$ Fru 2,6- $\mathrm{P}_{2} ; \Delta$, control plus $0.1 \mathrm{mM}-\mathrm{AMP}$ and $0.2 \mu \mathrm{M}-\mathrm{Fru} 2,6-\mathrm{P}_{2}$. ATP concentration in all experiments was $0.1 \mathrm{mM}$. All results shown were taken from a single experiment, but repetition yielded consistent results.

Fig. 3. Effect of Fru 6-P concentration on citrate-inhibited PFK activity as influenced by various effectors in the absense $(a)$ or presence $(b)$ of $20 \mathrm{mM}-\mathrm{NH}_{4}^{+}$. Symbols as in Fig. 2. All conditions were as described in Fig. 2, except that all assays were done in the presence of $5 \mathrm{~mm}$-citrate. 


\section{DISCUSSION}

The effects reported here of Fru 2,6- $\mathrm{P}_{2}$ on $A$. niger PFK are very similar to the effects observed with PFK from human erythrocytes, liver or muscle (Van Schaftingen et al., 1981; Uyeda et al., 1981; Heylen et al., 1982), but are at some variance with reports on the PFKs from $S$. cerevisiae (Bartrons et al., 1982) and P. blakesleeanus (Van Laere, 1983). This agrees with our previous assumption that PFK from $A$. niger is 'phylogenetically located between the yeast and the mammalian enzymes' (Habison et al., 1983). Differences between our results and those for $P$. blakesleeanus (Van Laere, 1983), the only other filamentous fungus so far investigated, could indicate further differences between lower and higher fungi; it must, however, be emphasized that Van Laere (1983) reported results obtained exclusively with crude cell-free extracts.

Our interest in the regulation of PFK from $A$. niger is related to the ability of this fungus to accumulate and secrete high concentrations of citrate (Röhr \& Kubicek, 1981). We have previously postulated that the ability of the fungus to maintain a high glycolytic hexose metabolism while accumulating intracellular concentrations of citrate of $4 \mathrm{~mm}$ depends on the intracellular accumulation of $\mathrm{NH}_{4}^{+}$ions, which are derived from increased proteolysis, and can antagonize citrate inhibition of PFK (Röhr \& Kubicek, 1981). In the light of our present results we are now able to support and detail this model: by looking at the effect of metabolites on the $[S]_{0.5}$ value of PFK for Fru 6-P, we can clearly state that the simultaneous presence of Fru 2,6$\mathrm{P}_{2}, \mathrm{AMP}$ and $\mathrm{NH}_{4}^{+}$is required to completely abolish the effect of citrate at concentrations resembling those found in $A$. niger mycelia during citric acid accumulation. This is not necessarily a contradiction of our previous postulation on the role on $\mathrm{NH}_{4}^{+}$ions in relation to the requirement for manganese-deficient cultivation conditions to enable $\boldsymbol{A}$. niger to accumulate citrate, since little difference has so far been detected in the mycelial contents of Fru 2,6- $\mathrm{P}_{2}$ and AMP under manganese-deficient and -sufficient conditions (unpublished results). The requirement for Fru 2,6-P $\mathrm{P}_{2}$ and AMP to allow PFK to be active in the presence of citrate may, however, limit glycolytic flow to citric acid under other physiological conditions. As an example, it is well documented (Kubicek \& Röhr, 1986) that citric acid accumulation in excessive amounts only occurs upon cultivation on media containing glucose or another readily metabolizable carbon source. Little acidogenesis occurs on galactose or lactose. This coincides well with Fru 2,6- $\mathrm{P}_{2}$ only being synthesized in the presence of extracellular glucose (Hers \& Van Schaftingen, 1982). It might thus be speculated that the effect of carbon source on citric acid accumulation is mediated by Fru 2,6- $\mathrm{P}_{2}$.

We believe that closer investigations of the metabolism of Fru 2,6- $\mathrm{P}_{2}$ and AMP in A. niger should contribute considerably to the elucidation of the fine regulation of carbon flow and acidogenesis in this fungus.

This work was supported by Schwerpunktsprogramm Biotechnologie of the Österreichisches Bundesministerium für Wissenschaft und Forschung, project P 9261. E. A. gratefully acknowledges a grant from the AustrianNetherlands exchange programme.

\section{REFERENCES}

Bartrons, R., Van Schaftingen, E., Vissers, S. \& HERS, H.-G. (1982). The stimulation of yeast phosphofructokinase by fructose 2,6-bisphosphate. FEBS Letters 143, 137-140.

Habison, A., KubiceK, C. P. \& RöHR, M. (1979). Phosphofructokinase as a regulatory enzyme in citric acid producing Aspergillus niger. FEMS Microbiology Letters 5, 39-42.

Habison, A., Kubicek, C. P. \& Röhr, M. (1983). Partial purification and regulatory properties of phosphofructokinase from Aspergillus niger. Biochemical Journal 209, 669-676.

Hers, H.-G. \& Van Schaftingen, E. (1982). Fructose2,6-bisphosphate two years after its discovery. Biochemical Journal 206, 1-12.
Heylen, A., Van Schaftingen, E. \& Hers, H.-G. (1982). The stimulation of phosphofructokinase from human erythrocytes by fructose 2,6 bisphosphate. FEBS Letters 143, 141-143.

KUBICEK, C. P. \& RöHR, M. (1978). The role of the tricarboxylic acid cycle in citric acid accumulation by Aspergillus niger. European Journal of Applied Microbiology and Biotechnology 5, 263-271.

KUBICEK, C. P. \& RöHR, M. (1986). The citric acid fermentation. CRC Critical Reviews in Biotechnology 3, 331-371.

Kubicek, C. P., Hampel, W. \& Röhr, M. (1979). Manganese deficiency leads to elevated amino acid pool levels in citric acid accumulating Aspergillus niger. Archives of Microbiology 123, 73-79. 
MeiXner-Monori, B., Kubicek, C. P. \& RöHR, M. (1984). Pyruvate kinase from Aspergillus niger: a regulatory enzyme in glycolysis? Canadian Journal of Microbiology 30, 16-23.

OGaWA, Y. \& ATKInson, D. E. (1985). Interactions between citrate and nucleoside triphosphates in binding to phosphofructokinase. Biochemistry 24, 954-958.

RöHR, M. \& KUBICEK, C. P. (1981). Regulatory aspects of citric acid fermentation by Aspergillus niger. Process Biochemistry 16, 34-37.

SCHREFERL, G., KubiceK, C. P. \& RöHR, M. (1986). Inhibition of citric acid accumulation by manganese ions in Aspergillus niger mutants with reduced citrate control of phosphofructokinase. Journal of Bacteriology 165, 1019-1022.

UYEDA, K. (1979). Phosphofructokinase. Advances in Enzymology and Related Areas of Molecular Biology 48, 193-244.

UyedA, K., Furuya, E. \& Luby, L. J. (1981). The effect of natural and synthetic D-fructose-2,6-bisphosphate on the regulatory kinetic properties of liver and muscle phosphofructokinases. Journal of Biological Chemistry 256, 8394-8399.

VAN LAERE, A. J. (1983). Stimulation of phosphofructokinase from Phycomyces blakesleeanus and some other fungi by micromolar concentrations of fructose 2,6-bisphosphate. Journal of General Microbiology 129, 3281-3285.

Van Schaftingen, E., Hue, L. \& Hers, H.-G. (1980a). Control of the fructose 6-phosphate/fructose 1,6bisphosphate cycle in isolated hepatocytes by glucose and glucagon. Biochemical Journal 192, 887-895. Van Schaftingen, E., Hue, L. \& Hers, H.-G. $(1980 \mathrm{~b})$. Fructose 2,6-bisphosphate, the probable structure of the glucose and glucagon sensitive stimulator of phosphofructokinase. Biochemical Journal 192, 897-901.

Van Schaftingen, E., Jett, M.-F., Hue, L. \& Hers, H.-G. (1981). Control of liver 6-phosphofructokinase by fructose-2,6-bisphosphate and other effectors. Proceedings of the National Academy of Sciences of the United States of America 78, 3483-3486. 